\title{
LEGISLAÇÃO NO COMBATE AO EXTREMISMO RELIGIOSO: O EXEMPLO DO
}

\author{
AZERBAIJÃO
}

Emanuelle Luana De Nadal Luzl Cláudio Antônio Klaus Júnior ${ }^{2}$

Recebido em: 21 out. 2019 Aceito em: 05 dez. 2019

\begin{abstract}
RESUMO
A religião é um fenômeno social que emergiu tanto como sistema de crenças quanto como forma de gestão da sociedade por muitos séculos. Dado que mais de dois terços da população mundial são crentes de diferentes religiões, as relações entre religião e estado, bem como religião e sociedade, sempre manterão sua atualidade. Para manter a paz, a tolerância e o multiculturalismo no mundo atual, existe uma grande necessidade de distinguir a liberdade de fé do radicalismo religioso, do extremismo religioso e do fanatismo. $\mathrm{O}$ direito como regulador das relações sociais, visa assegurar a sobrevivência, os direitos individuais, às liberdades individuais e tornar-se previsível e legítimo. A legislação e os estatutos nascem do direito para que, de forma pública e registrada, as pessoas possam conhecer as regras da sociedade em que vivem. Utilizando-se de conceitos de direito e legislação este trabalho visa expor o exemplo do Azerbaijão em seu direito nacional agindo como protetor das liberdades individuais. O Azerbaijão é localizado na região da Transcaucásia da Eurásia, entre a Ásia Ocidental e a Europa Oriental, marcado pelo multiculturalismo, é uma referência na legislação em combate ao extremismo religioso. Um panorama histórico do país é apresentado para a compreensão da evolução histórica que culmina na atual cultura da tolerância e aceitação do multiculturalismo. Palavras chave: Estado de direito, liberdade religiosa, multiculturalismo do Azerbaijão
\end{abstract}

\section{LEGISLATION IN COMBATING RELIGIOUS EXTREMISM: THE EXAMPLE OF}

\section{AZERBAIJAN}

\section{ABSTRACT}

Religion is a social phenomenon that has emerged as both a belief system and a way of managing society for many centuries. Since more than two-thirds of the world's population are believers of different religions, the relationship between religion and state, as well as religion and society, will always remain current. To maintain peace, tolerance, and multiculturalism in today's world, there is a great need to distinguish freedom of faith from religious radicalism, religious extremism, and fanaticism. Law as the regulator of social relations aims to ensure survival, individual rights, individual freedoms and to become predictable and legitimate. The legislation and statutes are born from the law so

\footnotetext{
${ }^{1}$ Bacharel em Relações Internacionais da Universidade do Vale do Itajaí.

${ }^{2}$. Acadêmico do curso de Relações Internacionais do Centro Universitário Internacional UNINTER, Pesquisador do Programa de Iniciação Científica do Centro Universitário Internacional UNINTER, Acadêmico do curso de Direito da Universidade Alto Vale do Rio do Peixe - UNIARP
} 
that, in a public and registered form, people can be aware of the rules of the society where they live. Azerbaijan is located in the Transcaucasian region of Eurasia, between Western Asia and Eastern Europe, marked by multiculturalism, and is a reference in legislation to combat religious extremism. Using concepts of law and legislation this work aims to set the example of Azerbaijan in its national law acting as a protector of individual freedoms. A historical overview of the country is presented for the understanding of the historical evolution that culminates in the current culture of tolerance, acceptance and multiculturalism.

Keywords: The rule of law, religious freedom, Azerbaijan multiculturalism

\section{INTRODUÇÃO}

O termo extremismo religioso descreve ações baseadas na fé que são tentativas deliberadas de causar danos, de modo geral, a outras pessoas. Inclui movimentos religiosos violentos que realizam ações que iniciam-se em comportamentos familiares abusivos, chegando a violência contra outras pessoas e culturas até ataques terroristas e ações genocidas. A tolerância religiosa, o multiculturalismo e a igualdade são os alvos particulares dos extremistas.

Grupos de extremistas religiosos existentes e atuantes no mundo contemporâneo apelam às suas próprias questões históricas nacionais para justificar seus atos. Um ponto comum marcante em grupos extremistas é que eles encorajam o papel da vida após a morte e banalizam a vida neste plano. O combate ao extremismo religioso é realizado nas mais diversas esferas e por diversas ações, neste trabalho é exposta a legislação como ferramenta para o combate.

O Azerbaijão após sua independência em 1991, recebeu missionários e instituições religiosas da região, vindos ao país com o intuito de difundir seus ideais religiosos. Houve uma formação basicamente islâmica por conta da forte influência do Irã, além da influência iraniana como uma estratégia contra possíveis ações "hostis" por parte do Azerbaijão ou caso o país se aliasse aos Estados Unidos. Ações religiosas, na maioria, ineficazes devido aos fortes resquícios da polícia antireligiosa deixada pelo domínio da União Soviética.

Atualmente com diversas ações nacionais em favor do multiculturalismo e em combate ao extremismo, o país é estudado mundialmente pelo seu exemplo legislacional. O objetivo do trabalho é expor o exemplo do Azerbaijão no combate ao extremismo religioso pelo uso do direito. Resulta de pesquisa bibliográfica sobre o extremismo religioso e seu combate através de legislação nacional, observada sob diferentes ângulos. As seções abordam a função do direito, a história do extremismo religioso no Azerbaijão e o exemplo do país no combate ao extremismo através da legislação.

\section{A FUNÇÃO DO DIREITO E DA LEI}

O direito é, segundo Miguel Reale, "um fato ou fenômeno social; não existe senão na Ponto de Vista Jurídico | Caçador | v.8 | nº 2 | p. 7-19 | jul./dez. 2019 
sociedade e não pode ser concebido fora dela. Uma das características da realidade jurídica é, como se vê a sua sociabilidade, a sua qualidade de ser social" (REALE, 2011, p. 2).

Historicamente observa-se que, desde o Código de Hammurabi, eram mencionadas sanções para o descumprimento de regras sociais. As regras dispostas no código mostravam que o direito punitivo era o que preponderava: "Se alguém roubar a propriedade de um templo ou da corte, ele será morto, e também quem receber dele o objeto roubado será morto" (YALE LAW SCHOOL: LILLIAN GOLDMAN LAW LIBRARY, 2019).

O direito surge [ainda] como regulador das relações sociais, nasce como uma necessidade humana visando assegurar a própria sobrevivência dentro de uma coletividade. Tais normas, que compõem a ordem jurídica e a todos são impostas, providenciando a segurança necessária às boas relações entre os membros de uma sociedade (FREIBERGER, 2018).

A ciência jurídica torna o direito viável. Ora, se o direito é um fenômeno social, a ciência jurídica também tem a sua função social. Desde o momento em que a sociedade politicamente organizada criou a regra de direito para ela se submeter, isto é reger as relações sociais, essas mesmas regras objetiva alcançar uma finalidade, uma função predisposta em suas estruturas dogmáticas (REALE, 2011).

Entende-se então que o direito é natural e também social. A contraposição do direito como fenômeno natural ou social não é possível, pois a sociedade, quando entendida como a real ou efetiva convivência entre os homens, pode ser pensada como parte da vida em geral e, portanto, como parte da natureza (KELSEN, 2006).

O direito surge também como subproduto da vida em sociedade e "como criação do espírito humano; criado pelos homens, aos homens se destina, regulando as suas ações e dirigindo-as ao fim supremo que é a realização do bem" (RUGGIEIRO, 1934, p. 21).

Sobre o direito, à organização ou ordem e o direito, Goffredo Telles Junior ensina:

Ora a lei é a ideia de ordem. É a fórmula elaborada por alguma inteligência, para a conveniente disposição de coisas, a fim de produzir um efeito preconizado. Toda lei é o plano concebido do que vai ou deve acontecer. É a fórmula da ordem, como dissemos (TELLES, 2006, p. 219-220).

A lei então é criada com o fim de obter ordem. “[...] Para que haja Direito, é necessário que haja, grande ou pequena, uma organização, isto é, um completo sistema normativo" (BOBBIO, 1991, p. 27). Desde quando do problema do Estado passaram a tomar conta os juristas, o Estado tem sido definido através de três elementos constitutivos: o povo, o território e a soberania. O Estado é um ordenamento jurídico destinado a exercer o poder soberano sobre um dado território, ao qual estão necessariamente subordinados os sujeitos a ele pertencentes (MORTATI, apud BOBBIO, 1985).

Há um tráfego de mão dupla entre direito e cultura popular. Questões jurídicas reais e 
controvérsias dão origem a representações legais populares, assim como as representações legais populares ajudam a informar e moldar questões legais reais e resultados de casos.

Carvalho esclarece sobre o assunto em pauta. Segundo ele,

\begin{abstract}
A função social do direito é o fim comum que a norma jurídica deve atender dentro de um ambiente que viabilize a paz social. O direito sempre teve uma função social. A norma jurídica é criada para reger relações jurídicas, e nisso, a disciplina da norma deve alcançar o fim para o qual foi criada. Se ela não atinge o seu desiderato, não há como disciplinar as relações jurídicas, e, portanto, não cumpre sua função, seu objeto. A função social do Direito é o fim comum a que a norma jurídica deve atender dentro de um ambiente que viabilize a paz social. Nisso, há que se ter presente que não há norma jurídica puramente individual, na medida em que ela regula relações humanas, sejam relações puramente de Direito privado, relações de ordem pública, coletivas e/ou difusas. Por meio da função social do Direito, o legislador objetiva humanizar as relações jurídicas, adotando novos valores que o mundo, em especial, o mundo ocidental, adotou com a evolução dos processos humanos e dos anseios das camadas sociais de alcançar melhores dias, pondo fim aos valores individualistas que presidiram os séculos XVII ao XIX e parte do século XX. Nesse processo de humanização, é vedado ao homem obter vantagens em descompasso com os comandos normativos (CARVALHO, 2011, pág. 1).
\end{abstract}

Com os conceitos de direito, ciência jurídica e função social pode definir-se que o direito cumpre um papel de direção de conduta, preventivo e punitivo (tratamento de condutas - gestão e solução) e a legislação trata-se de um conjunto de leis com valor jurídico, regularizando determinada matéria ou ciência, nos planos nacional e internacional, para assegurar estabilidade governamental e segurança jurídica às relações sociais entre cidadãos, instituições e empresas, que estabelece condutas e ações aceitáveis ou recusáveis de um indivíduo, instituição, entre outros. Sendo então a legislação um instrumento para que o direito possa exercer sua função. Montesquieu em "O Espírito das Leis" diz ainda que o fraco deve se proteger do forte através das leis.

Joaquín Herrera Flores leciona que:

O direito não vai surgir, nem funcionar, por si só. As normas jurídicas poderão cumprir uma função mais em concordância com o "que ocorre em nossas realidades" se as colocarmos em funcionamento - a partir de cima, mas sobretudo a partir de baixo -, assumindo desde o princípio uma perspectiva contextual e crítica, quer dizer, emancipadora (FLORES, 2009. p. 24).

Entende-se então que o direito e a legislação nascem da necessidade social e devem nortear a vida daqueles que se submetem a viver em territórios onde tal norma existe.

A legislação poderá ainda ser interna e aplicar-se a apenas um país ou internacional podendo ser adotada por outros através de tratados. Conforme ensina o jurista brasileiro Francisco Rezek (1989), "Tratado é o acordo formal, concluído entre sujeitos de direito internacional público, e destinado a produzir efeitos jurídicos" (REZEK apud SILVA, 2011). Nos séculos XX e XXI, intensificou-se o esforço internacional de produção de normas jurídicas escritas, de modo a garantir maior previsibilidade e legitimidade ao Direito Internacional (SILVA, 2011).

A própria Carta das Nações Unidas, assinada em 1945, em São Francisco, e que constitui 
um dos principais Tratados em vigor atualmente, estabelece que a organização empreenderá esforços para:

Promover cooperação internacional no terreno político e incentivar o desenvolvimento progressivo do direito internacional e a sua codificação (A Carta das Nações Unidas - Artigo 13; 1.a.)

Pode-se dizer ainda que um dos fins objetivados pela legislação e pelos códigos é a justiça - como enfatizado por Platão em "A República", no qual ele questiona "por que devemos ser virtuosos, e justos (em vez de maus)", e "por que devemos ser cumpridores da lei ou éticos" (PAVLICH, apud BIJOS, 2018) - a justiça é o traço mais forte da sociedade, contribuindo para o progresso do país, paz e segurança. Platão apresentou a ideia de justiça como o estado natural da sociedade civilizada e dos seres individuais. Ele vê a justiça como tendo uma natureza essencial e purificada que podemos decifrar pelo uso cuidadoso da razão e da lógica (PAVLICH, apud BIJOS, 2018).

Os países democráticos são parte de um sistema de governo por leis, não por indivíduos. Em uma democracia, o Estado de Direito protege os direitos dos cidadãos, mantém a ordem e limita o poder do governo. Todos os cidadãos são iguais nos termos da lei. O governo por leis tem diversos benefícios, em especial na garantia dos direitos fundamentais do cidadão, além da garantia de previsibilidade.

\section{PANORAMA HISTÓRICO DO EXTREMISMO RELIGIOSO NO AZERBAIJÃO}

Discussões acerca do extremismo religioso têm sido recorrentes no campo das Relações Internacionais principalmente após os ataques de 11 de setembro de 2011. Mesmo não sendo a causa determinante do terrorismo, a religião pode ser considerada um dos fatores agravantes para a intensificação de conflitos. Nesse sentido, a presente seção traz um breve retrato histórico do extremismo religioso no Azerbaijão e elucida seus possíveis reflexos na conjuntura atual.

O período pós Guerra Fria representou o aumento dos conflitos relacionados à religião, pois de certa forma substituíram as batalhas entre o Ocidente capitalista e o Bloco comunista (JUERGENSMEYER, 2001). Segundo o pensamento de Huntington em "O Choque de Civilizações",

[...] no mundo moderno, a religião é uma força central, talvez a força central que motiva e mobiliza as pessoas. O que em última análise conta para as pessoas não é a ideologia política nem o interesse econômico; mas aquilo que com que as pessoas se identificam são as convicções religiosas, a família e os credos. É por estas coisas que elas combatem e até estão dispostas a dar a sua vida (HUNTINGTON, 1997, p.79).

Nesse sentido, desafios quanto ao extremismo religioso emergiram na República do Azerbaijão. Ao se tornar independente em 1991 após a dissolução da União Soviética, missionários e 
instituições religiosas principalmente da Turquia, Irã e Mundo Árabe vieram ao país com o intuito de difundir seus ideais religiosos, alguns dos quais supostamente ligados à organizações militantes (GEORGIAN CENTER FOR SECURITY AND DEVELOPMENT, 2018).

O primeiro desafio a emergir naquele período refere-se a influência do Irã, país vizinho que buscava estabelecer os valores islâmicos no Azerbaijão e assim formular um partido político para influenciar a vida pública. Como parte dessa estratégia, organizações iranianas passaram a conceder ajuda humanitária e literatura religiosa em campos de refugiados e recrutar jovens azerbaijanos para estudar em escolas religiosas no Irã (GEORGIAN CENTER FOR SECURITY AND DEVELOPMENT, 2018).

Contudo, estas ações foram ineficazes devido a forte política anti-religiosa estabelecida no Azerbaijão durante o domínio da União Soviética ${ }^{3}$. As tentativas iranianas de estabelecer grupos radicais no país não necessariamente representavam a decisão de reproduzir ataques imediatos, mas constituíam-se em uma estratégia contra possíveis ações "hostis" por parte do Azerbaijão ou até mesmo caso o país se aliasse aos Estados Unidos (GEORGIAN CENTER FOR SECURITY AND DEVELOPMENT, 2018).

O segundo desafio em relação ao extremismo religioso no Azerbaijão é o Salafismo ${ }^{4}$, corrente sunita do Islã que defende um retorno ao Islã em sua forma mais pura. A influência desta corrente se deu através de missionários advindos do Daguestão e Chechênia (norte do Cáucaso) a partir de 1990 e também após a guerra russo-chechena, (1999 - 2001) ocasião em que rebeldes chechenos, em grande maioria de orientação salafista, foram empurrados pelos russos para fora do norte do Cáucaso em direção à Geórgia e Azerbaijão (SOULEIMANOV, EHRMANN, 2013).

A ação dos missionários salafis resultou em diversas cidades azerbaijanas convertidas à religião. Em 2003, por exemplo, 65 novas mesquitas comandadas por salafis foram criadas, o que mostra que tais ações foram fundamentais para a intensificação do movimento na região. Entre as organizações militantes (também conhecidas como jihadistas) estabelecidas naquele período no Azerbaijão, destaca-se o grupo Jeyshullah, que com o objetivo de tomar o poder e criar um estado islâmico, executou diversos ataques terroristas entre 1997 e 1999. Além deste, cita-se o Forest Brothers, grupo que buscava propagar o jihad militante através de livros e planejar ataques à

\footnotetext{
${ }^{3}$ Ao ocupar o Azerbaijão em 1920, a Rússia comunista implementou o ateísmo estatal na sociedade, tornando-a praticamente imune à manifestações em prol do islamismo político. Pesquisas no final da era soviética pontuaram que, embora a grande maioria dos azerbaijanos se identificasse como muçulmana, apenas uma pequena parcela tinha compreensão dos pilares do Islã (SOULEIMANOV, EHRMANN, 2013).

4 "O salafismo se originou como um movimento intelectual liderado por Muhammad Abduh, Jamal al-Din alAfghani e Rashid Rida no final do século XIX. Os primeiros Salafis tentaram consolidar o avanço tecnológico e social do Iluminismo da Europa, acreditando que sua própria sociedade era a herdeira da Idade de Ouro do Islã (período após as revelações do Profeta Muhammad)" (SOULEIMANOV, EHRMANN, 2013).
} 
instituições associadas ao Estado, que estava em ação ainda em 2012 (VALIYEV, 2018).

No panorama atual, estimativas apontam a existência de 10.000 a 25.000 adeptos ao salafismo no Azerbaijão. Contudo, as ações do movimento se limitam à pregação nas mesquitas, enquanto apenas uma parcela exerce atividades militantes, que por sua vez são limitadas devido à falta de recursos financeiros e de equipamentos. Assim, embora os ensinamentos salafistas contradigam o ramo xiita do Islã - seguido pela maioria da população - a maioria dos adeptos não se envolve em atividades criminosas (EUROPEAN FOUNDATION FOR DEMOCRACY, 2015; GEORGIAN CENTER FOR SECURITY AND DEVELOPMENT, 2018).

Ainda é importante ressaltar que, embora possua alcance limitado, o salafismo ainda apresenta preocupações. O governo do Azerbaijão hoje adota identidade secular, por isso, é frequentemente criticado pelo declínio dos valores morais tradicionais e aumento da criminalidade no país. Desta forma, os cidadãos podem se voltar ao movimento salafi como uma forma de oposição política ao regime atual. Em 2010, por exemplo, o Azerbaijão adotou um uniforme escolar padrão que excluía trajes islâmicos tradicionais. Tal ação provocou protestos nas ruas contra a discriminação do governo à muçulmanos devotos, e consequentemente constituiu-se em um possível estímulo ao movimento (SOULEIMANOV, EHRMANN, 2013; VALIYEV, 2018). Nesse sentido, a próxima seção aborda as respostas do país frente às ameaças de extremismo religioso e expõe a legislação estatal utilizada, baseada em grande medida nos princípios de multiculturalismo e tolerância.

\section{O EXEMPLO DO AZERBAIJÃO NO COMBATE AO EXTREMISMO RELIGIOSO}

O Azerbaijão é um exemplo raro em um país de maioria muçulmana. O primeiro artigo de sua Constituição afirma que "a República do Azerbaijão se proclama um estado democrático, secular, legal e social cujos valores mais altos são um indivíduo, sua vida, direitos e liberdades" (WOONS, 2017, p. 125) ${ }^{5}$. Contudo, esta não é uma tarefa fácil haja vista a extensa diversidade cultural e religiosa do país.

Atualmente o Azerbaijão engloba cerca de 30 grupos étnicos, compostos principalmente por turcos, talishes, curdos, ávaros, tártaros, tats e udins. Estima-se que $93 \%$ da população é muçulmana (sendo que $65 \%$ são xiitas e 35\% sunitas), 3,1\% é cristã (confissões ortodoxas, católicas e protestantes), e o restante representa minorias religiosas como Bahais, Krishnaitis, Zoroastrianos, entre outros (MAMMADZADEH et al., 2018).

\footnotetext{
${ }^{5}$ Texto original: "The Republic of Azerbaijan proclaims itself a democratic, secular, legal and social state whose highest values are an individual, his life, rights and freedoms". Todas as traduções feitas no presente artigo são de responsabilidade dos autores.
} 
À vista disso, com o intuito de destacar seu apoio à diversidade cultural e religiosa, o presidente do Azerbaijão Ilham Aliev declarou 2016 "O ano do Multiculturalismo” no país. Ainda, em 2015 estabeleceu o Baku International Multiculturalism Center $^{6}$, organização que regula as relações étnicas e religiosas no território e divulga o modelo do multiculturalismo azerbaijano no exterior. Segundo o presidente, o Azerbaijão representa uma ponte cultural entre o Oriente e Ocidente e, embora nos séculos passados não houvesse a palavra multiculturalismo, as ideias que o retratam já estavam presentes (MAMMADZADEH et al., 2018).

Assim, entender a abordagem secular e tolerante do Azerbaijão pressupõe visualizar sua história, que remete principalmente ao período em que a Rússia czarista obteve controle sobre o país em 1828. A partir deste período, o território se tornou um dos líderes mundiais na produção de petróleo, houve aumento da atividade econômica com a Europa e a vinda de colonos russos para a região. Esse ambiente propiciou, como consequência, a entrada de novas ideias no país. Desta forma, apesar da presença marcante de muçulmanos xiitas e sunitas, os intelectuais do Azerbaijão, inspirados pelas ideias advindas da Europa passaram a promover uma visão de Estado secular, que se materializou posteriormente em 1918, quando a República Democrática do Azerbaijão se tornou a primeira democracia secular no mundo muçulmano (NAJAFIZADEH, 2012, apud WOONS, 2017).

A partir disso, o país garantiu que grupos etnoculturais e religiosos teriam representação garantida, proporcionando-lhes assentos parlamentares ${ }^{7}$. Em conformidade com Woons, $(2017$, p. 124)

[...] isso levou o povo do Azerbaijão a tomar inúmeras decisões políticas fundamentais que promoviam a paz, a tolerância e a inclusão não apenas entre a maioria étnica do Azerbaijão ou muçulmana, mas também muitas outras minorias ${ }^{8}$.

Diferentemente de conceitos ocidentais, o Azerbaijão então formulou uma política de Estado que envolvia tanto o conhecimento liberal quanto o Islã tradicionalista (ISMAYILOV, 2015). Entretanto, com o advento da ocupação Soviética, essa abordagem deixa de ser prioridade devido ao expressivo ateísmo estatal implantado pelo governo, mencionado na seção anterior.

Com o colapso da URSS, O Azerbaijão restabeleceu sua independência e, como conseguinte, adotou em sua Constituição o princípio de que todas as fés são iguais perante a lei na relação estado-religião (MAMMADZADEH et al., 2018). Além disso, concebeu

\footnotetext{
${ }^{6}$ Em tradução para português: Centro Internacional de Multiculturalismo de Baku.

${ }^{7}$ Do total de 120 assentos parlamentares, 21 foram destinados à armênios, 10 para russos e um para as populações étnicas alemãs e judaicas (CORNELL; KARAVELI; AJEGANOV, 2016).

${ }^{8}$ Texto original: "All of this led the people of Azerbaijan to pursue numerous fundamental political decisions that promoted peace, tolerance, and inclusion not just among the ethnic Azerbaijani or Muslim majority, but many other minorities".
} 
ferramentas para enfrentar possíveis ameaças de radicalização e assim garantir um equilíbrio entre a estabilidade e o desenvolvimento da diversidade.

Como parte dessa estratégia, o Azerbaijão atualmente adota instrumentos legais com o intuito de monitorar as atividades religiosas e assim evitar a ocorrência de extremismos. A Constituição do país garante explicitamente o princípio do secularismo, tanto em seu preâmbulo quanto no artigo 7, que define o Estado como uma "república democrática, legal, secular e unitária" (THE CONSTITUTION OF THE REPUBLIC OF AZERBAIJAN, p. 3) ${ }^{9}$. O Art. 18 que explica que a religião é separada do governo e cada religião é igual perante a lei (BIJOS, 2018). O artigo 25 garante os mesmos direitos a todos os cidadãos, independentemente de sua crença religiosa, enquanto o artigo 48 prevê a liberdade religiosa e o direito de professá-la (CORNELL; KARAVELI; AJEGANOV, 2016).

Além disso, os valores da Constituição encontram complementaridade na Lei sobre a Liberdade de Crenças Religiosas de 1992, que estabelece o princípio da liberdade de religião e, ao mesmo tempo, objetiva impedir que esta seja utilizada contra a natureza secular do Estado. O artigo 1 estabelece que "[...] é proibido propagar as religiões com o uso de violência religiosa ou semear discórdia entre as pessoas com o objetivo de mudar seu modo de vida religioso ou forçar a confissão de religião"10 (EUROPEAN FOUNDATION FOR DEMOCRACY, 2015, p. 57).

Todos têm o direito de praticar sozinhos ou em qualquer outra religião, de expressar e disseminar suas convicções a respeito da relação da religião. A Lei da Liberdade Religiosa repete os princípios seculares da Constituição, mas também procura estabelecer barreiras legais contra a destruição do estado secular do Azerbaijão por atores religiosos. Assim, condiciona o princípio da liberdade de religião à intocabilidade absoluta do estado secular (CORNELL; KARAVELI; AJEGANOV, 2016).

Ainda, em 5 de dezembro de 2015, o país adotou uma lei especial "Sobre a luta contra o extremismo religioso". Ao definir as bases legais e organizacionais da luta contra o extremismo religioso, a lei fixa os direitos e obrigações dos órgãos e cidadãos do Estado que realizam a luta contra o extremismo (HASANOV, 2019).

O principal objetivo da adoção desta lei é proteger a estrutura constitucional, a soberania e a segurança multicultural do Estado e fortalecer a luta contra grupos armados e organizações

\footnotetext{
${ }^{9}$ Texto original: "Article 7. Azerbaijanian state 1. Azerbaijanian state is democratic, legal, secular, unitary republic".

${ }^{10}$ Texto original: "It is prohibited to propagandise religions with the appliance of religious violence or sowing discord among the people with the aim of changing their religious way of life or forcing to confessing religion".
} 
terroristas formadas em disfarces religiosos. Dado que grupos terroristas estão em ascensão com ideias radicais, a adoção da lei mencionada foi de grande importância (HASANOV, 2019).

Em decisão do Tribunal Distrital de Nasimi, cidade de Baku, de 4 de agosto de 2017, foi pronunciado:

[A] República do Azerbaijão em sua Constituição declara que seu objetivo mais alto é garantir os direitos e as liberdades humanas, estabelece o dever dos tribunais de restaurar os direitos e as liberdades humanas - e em conformidade com o artigo 41 da Convenção e a jurisprudência do Tribunal Europeu, quando os direitos humanos e as liberdades são violados, para restaurar o estado anterior apenas com satisfação11.

A decisão mostrou novamente o Estado como soberano e cumpridor daquilo que expressa em sua constituição. O Diretor do Centro Internacional de Multiculturalismo do Azerbaijão Ravan Hasanov menciona:

Como um estado civil e secular, o Azerbaijão sempre foi contra o extremismo religioso, condenou a intolerância religiosa e cooperou com outros estados nesta esfera e o faz hoje também. O Azerbaijão dá preferência à cooperação com os países que combatem o terrorismo e o extremismo religioso. Atualmente, os órgãos de aplicação da lei estão adotando medidas consistentes e direcionadas para impedir as tendências radicais e extremistas.(HASANOV, 2019) ${ }^{\mathbf{1 2}}$.

Tal monitoramento das atividades religiosas ocorre através do Conselho Muçulmano do Cáucaso e do Comitê Estadual para o Trabalho com Organizações Religiosas, órgãos que buscam garantir que as ações relacionadas à religião estejam em conformidade com a lei. Além destes, o Ministério da Segurança Nacional e os serviços de inteligência supervisionam clérigos radicais que por vezes utilizam mesquitas e organizações religiosas para recrutar indivíduos para a militância (EUROPEAN FOUNDATION FOR DEMOCRACY, 2015).

Deste modo, apesar da coexistência estável e pacífica na República do Azerbaijão, a ameaça do extremismo religioso e o radicalismo existe em todos os locais. Para evitar isso, as tradições de tolerância e multiculturalismo devem ser mantidas, desenvolvidas e defendidas em toda a sociedade (HASANOV, 2019).

\footnotetext{
${ }^{11}$ Texto original: "[The] Azerbaijan Republic in its Constitution declares its highest aim is to guarantee human rights and freedoms, establishes the duty of the courts to restore human rights and freedoms-and in accordance with Article 41 of the Convention and the European Court case-law, when human rights and freedoms are violated, to restore to the previous state by means of just satisfaction"- Baku City Nasimi District Court, decision dated August 4, 2017.

${ }^{12}$ Texto original: "As a civil and secular state, Azerbaijan has always been against religious extremism, condemned religious intolerance and cooperated with other states in this sphere and is doing it today as well. Azerbaijan gives preference to cooperation with the countries combating terrorism, religious extremism. At present legal enforcement bodies are taking consistent and targeted measures to prevent the radical and extremist tendencies" (Hasanov, 2019).
} 


\section{CONCLUSÃO}

Diante dos expostos acima, foi possível demonstrar a importância da legislação do Azerbaijão no combate ao extremismo religioso. Essa asserção foi viabilizada por meio do estudo da legislação vigente e contexto histórico do país. A partir do entendimento da expressiva diversidade religiosa e cultural, assimilou-se que políticas que visam a tolerância e a promoção do multiculturalismo dispõem de vantagens reais.

Compreendeu-se que embora o nível de extremismo religioso no país seja considerado relativamente baixo, a conjuntura é volátil devido a presença da ideologia islâmica radical no país, citada no contexto histórico e, de maneira geral, por conta da ascensão de grupos terroristas na contemporaneidade, fatores que intensificam a importância de instrumentos legais que priorizem a segurança.

Apesar dos benefícios, arrisca-se inferir que a tolerância a todas as religiões encontra respaldo somente naquelas compatíveis com a ideologia secular do Estado. Por isso, percebe-se que o Azerbaijão apoia as religiões minoritárias desde que estas pressuponham um relacionamento de cooperação com os valores estatais, prática que pode limitar o alcance e livre expressão de tais organizações religiosas.

Ainda, ao término deste trabalho foi possível analisar a escassez de produções acadêmicas no tocante ao tema na academia brasileira. Desta forma, pretende-se que o artigo em questão suscite outras pesquisas referentes à política de estado multicultural do Azerbaijão.

\section{REFERÊNCIAS}

BIJOS, Leila. O papel do multiculturalismo na política de Estado do Azerbaijão, Editora Espaço Acadêmico, 2018.

BOBBIO, Norberto. Estado, Governo, Sociedade.1985, p. 93. Rio de Janeiro: Editora Paz e Terra.

BOBBIO, Norberto. Teoria do ordenamento jurídico. 1991. p. 27. Brasília: Editora Universidade de Brasília - Editora Polis.

CARVALHO, Francisco José. A função social do Direito e a efetividade das Normas Jurídicas. Introdução ao Estudo do Direito. Carta Forense. 2011, p. 36. Disponível em: $<$ http://www.cartaforense.com.br/conteudo/artigos/a-funcao-social-do-direito-e-a-efetividadedas-normas-juridicas/7940>. Acesso em: 20 set. 2019.

CIFUENTES, Rafael Llano. Relações entre a Igreja e o Estado. 2. ed. Rio de Janeiro, José Olympio, 1989.

CORNELL, Svante; KARAVELI, Halil; AJEGANOV, Boris. Azerbaijan's Formula: 
Secular Governance and Civic Nationhood. Singapura: Central Asia-Caucasus Institute and Silk Road Studies Program, 2016. 110 p.

European Foundation for Democracy. Secularism in Azerbaijan and the Threat of Radicalization in the Region. Bruxelas: European Foundation For Democracy, 2015. p.77

FREIBERGER, Rubens Luìs. AUDIÊNCIAS DE CUSTÓDIA NO BRASIL: UMA APRESENTAÇÃO DESTE INSTITUTO OBSERVANDO-SE OS PRINCÍPIOS DE DIREITO PENAL E AS PRISÕES PENAIS DO ORDENAMENTO JURÍDICO BRASILEIRO. Revista Ponto de Vista Jurídico: Revista Científica do Núcleo de Pesquisa em Direito da UNIARP, Caçador, v. 7, n. 1, jun./2018. Disponível em: $<$ http://dx.doi.org/10.33362/juridico.v7i1.1494>. Acesso em: 20 set. 2019.

GEORGIAN CENTER FOR SECURITY AND DEVELOPMENT. The Roots of Violent Extremism and Radicalization in Azerbaijan and Georgia. Tbilisi: Friedrich-ebertstiftung, 2018. Disponível em: <http://library.fes.de/pdf-files/bueros/georgien/14736.pdf>. Acesso em: 10 out. 2019.

HASANOV, RAVAN - EURASIA REVIEW. Role of Multiculturalism Policy in Struggle Against Religious Extremism: Example Of Azerbaijani Experience - Analysis.

Disponível em: <https://www.eurasiareview.com/07042019-role-of-multiculturalism-policyin-struggle-against-religious-extremism-example-of-azerbaijani-experience-

analysis/?fbclid=IwAR0hq9JGSbu-

dPerzOPkHOMadagZcsELVNBPHZS6WZwS6y9x4tUls4dHHDs>. Acesso em: 16 out. 2019.

HUNTINGTON, Samuel P. O choque de civilizações. São Paulo: Ed. Objetiva, 1997.

ISMAYILOV, Murad. Postcolonial Hybridity, Contingency, and the Mutual Embeddedness of Identity and Politics in Post-Soviet Azerbaijan: Some Initial Thoughts. Caucasus Analytical Digest. Zurique, p. 7-13. set. 2015.

JUERGENSMEYER, Mark. O Terror na Mente de Deus: $O$ crescimento global da violência religiosa. $3^{\mathrm{a}}$ ed. University of California Press, 2001.

KELSON, Hans. Teoria Pura do Direito. $7^{\mathrm{a}}$ ed. São Paulo: Martins Fontes, 2006. p. 1-427.

MAMMADZADEH, Ilham et al. The multicultural nature of Azerbaijani space as seen by exponents of Azerbaijani culture. Geopolitical, Social Security And Freedom Journal. Varsóvia, p. 27-36. set. 2018.

REALE, Miguel. Lições Preliminares de Direito. 25. ed. São Paulo: Saraiva, 2011. p. 1-371. RUGGIEIRO, Roberto de. Instituições de Direito Civil. São Paulo: Saraiva, 1934, p. 21.

SILVA, Elaini Cristina Gonzaga da. A EXPANSÃO DO DIREITO INTERNACIONAL: Uma questão de valores. Tese (Doutorado em Direito Internacional) - Faculdade de Direito, Universidade de São Paulo. São Paulo, p. 11. 2011.

SOULEIMANOV, Emil; EHRMANN, Maya. The Rise of Militant Salafism in Azerbaijan and Its Regional Implications. Middle East Policy Council. Washington D.C., p. 111-120. set. 2013. 
TELLES Jr, Goffredo. Direito Quântico. 8ª ed. São Paulo: Editora Juarez de Oliveira, 2006. p. 219-220.

THE CONSTITUTION OF THE REPUBLIC OF AZERBAIJAN. The Constitution of the Republic of Azerbaijan. Disponível em:

$<$ http://azerbaijan.az/portal/General/Constitution/doc/constitution_e.pdf $>$. Acesso em: 18 out. 2019.

US DEPARTMENT OF STATE. 2018 Report on International Religious Freedom:

Azerbaijan. Disponível em: <https://www.state.gov/reports/2018-report-on-internationalreligious-freedom/azerbaijan/>. Acesso em: 8 out. 2019.

VALIYEV, Anar. Islamic Movements in Azerbaijan. 2018. Disponível em:

$<$ https://mesbar.org/islamic-movements-in-azerbaijan/>. Acesso em: 14 out. 2019.

WOONS, Marc. Multiculturalism at the Crossroads: Learning Beyond the West. In: WOONS, Marc; WEIER, Sebastian. Critical Epistemologies of Global Politics. Bristol: Einternational Relations Publishing, 2017. Cap. 7. p. 116-133.

YALE LAW SCHOOL: LILLIAN GOLDMAN LAW LIBRARY. The Code of Hammurabi. Disponível em: $<$ https://avalon.law.yale.edu/ancient/hamframe.asp $>$. Acesso em: 22 set. 2019. 